\title{
Quantification of LVEF $\leq 35 \%$ misclassification by 2D-echocardiography as compared to cardiac magnetic resonance in coronary artery disease: implications for AICD therapy
}

\author{
Diane J Parrington, Aramesh Saremi, Sudhakar V Girotra, Sandesh Dev, Charles Oh, Cynthia L Scott, \\ Raymond Q Migrino*
}

From 15th Annual SCMR Scientific Sessions

Orlando, FL, USA. 2-5 February 2012

\section{Background}

Cardiac magnetic resonance (CMR) is the noninvasive gold standard for evaluation of LV size/function due to its low interscan/intraobserver/interobserver variability. However, 2D echocardiography (Echo) remains the modality of choice to assess LV function due to ease of use, cost-effectiveness and ubiquity despite its known higher method variability. Randomized trials showed that automated implantable cardiac defibrillators (AICD) provide survival benefit in ischemic/nonischemic cardiomyopathy patients with LV ejection fraction (EF) $\leq 35 \%$. It is therefore important to correctly classify patients by LVEF $\leq 35 \%$ status to avoid improper placement or withholding of placement of AICD. We aim to quantify the misclassification of LVEF $\leq 35 \%$ by Echo when compared to CMR in ischemic cardiomyopathy patients.

\section{Methods}

Ischemic cardiomyopathy ( $\mathrm{LVEF}<40 \%)$ patients had cardiac imaging at baseline and following 6 months of micronutrient supplementation on top of optimal medical therapy as part of a dietary supplementation study. Sixteen sets of same-day CMR and Echo scans were compared (from 8 subjects, all males, $71 \pm 8$ years). LVEF was measured in CMR using cardiac-gated steady state free precession gradient echo cine and modified Simpson's method, while biplane volumetric method was used in Echo. Correlation, ROC curve and kappa analyses were used.

Phoenix VA, Phoenix, AZ, USA

\section{Results}

LVEF was $30.7 \pm 9.4 \%$ (CMR) and $28.3 \pm 9.0 \%$ (Echo) $(\mathrm{R}=0.93, \mathrm{p}<0.0001)$. CMR classified $10 / 16$ while Echo classified $10 / 16$ as having $\mathrm{LVEF} \leq 35 \%$. Using CMR as gold standard, Echo misclassified $2(12.5 \%)$ as having LVEF $\leq 35 \%$ and misclassified $1(6.2 \%)$ as having LVEF $>35 \%$. Kappa statistic for CMR and echo for $\mathrm{LVEF} \leq 35 \%$ is 0.59 , denoting moderate classification agreement. By ROC analysis, an echo EF cutoff of $29 \%$ has $80 \%$ sensitivity, $100 \%$ specificity for detecting CMR $\mathrm{LVEF} \leq 35 \%$ with AUC of 0.92 (95\%CI $0.67-0.99$, $\mathrm{p}=0.001$, see figure).

\section{Conclusions}

Despite high correlation, Echo misclassified LVEF $\leq 35 \%$ in $18.75 \%$ of cardiomyopathy cases versus CMR. With 1.2 million MI patients per year in the US and published data of $11 \%$ of MI patients having $\mathrm{LVEF} \leq 35 \%$ 90-days after MI, 132,000 patients potentially require AICD annually. Misclassification of LVEF $\leq 35 \%$ by Echo has substantial implications for delivery or withholding of AICD therapy and the prognostic implications need to be formally studied. Short of using CMR in all post-MI patients, based on ROC analysis the misclassification can potentially be minimized by measuring CMR LVEF in patients with Echo $\mathrm{EF} \geq 30-40 \%$.

\section{Funding}

VISN 18 (Veterans Affairs) New Investigator Award. 


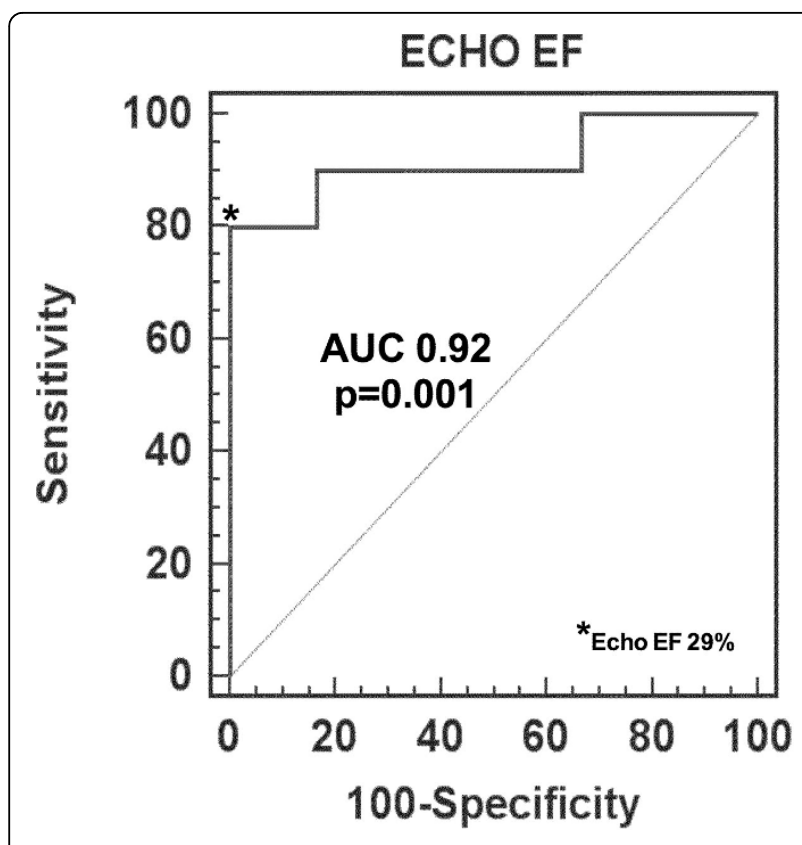

Figure 1 ROC curve analysis of Echo EF predicting CMR EF $\leq 35 \%$. Echo $E F \leq 29 \%$ has $80 \%$ sensitivity and $100 \%$ specificity for predicting CMR EF $\leq 35 \%$.

\section{doi:10.1186/1532-429X-14-S1-P212}

Cite this article as: Parrington et al:: Quantification of $\mathrm{LVEF} \leq 35 \%$ misclassification by $2 \mathrm{D}$-echocardiography as compared to cardiac magnetic resonance in coronary artery disease: implications for AICD therapy. Journal of Cardiovascular Magnetic Resonance 2012 14(Suppl 1): P212.

Submit your next manuscript to BioMed Central and take full advantage of:

- Convenient online submission

- Thorough peer review

- No space constraints or color figure charges

- Immediate publication on acceptance

- Inclusion in PubMed, CAS, Scopus and Google Scholar

- Research which is freely available for redistribution

Submit your manuscript at www.biomedcentral.com/submit 